Case report

\title{
Postnatal onset of severe growth retardation after in utero exposure to carbamazepine and phenobarbital: a case report Alice Liguori and Stefano Cianfarani*
}

Address: 'Rina Balducci' Center of Pediatric Endocrinology, Department of Public Health and Cell Biology, Tor Vergata University, 00133-Rome, Italy

Email: AL - aliceliguori@tiscali.it; SC* - stefano.cianfarani@uniroma2.it

* Corresponding author

Received: 19 February 2008 Accepted: 23 January 2009 Published: 12 June 2009

Journal of Medical Case Reports 2009, 3:7300 doi: 10.4076/1752-1947-3-7300

This article is available from: http://jmedicalcasereports.com/jmedicalcasereports/article/view/7300

(C) 2009 Liguori and Cianfarani; licensee Cases Network Ltd.

This is an Open Access article distributed under the terms of the Creative Commons Attribution License (http://creativecommons.org/licenses/by/3.0),

which permits unrestricted use, distribution, and reproduction in any medium, provided the original work is properly cited.

\begin{abstract}
Introduction: Anticonvulsant drugs taken by pregnant women to prevent seizures are among the most common causes of potential harm to the fetus. While the immediate harmful effects manifesting as congenital abnormalities are well known, the long-term effects on growth of children exposed in utero to antiepileptic drugs are still uncertain.

Case presentation: A 7-year-old boy presented to our clinic with severe short stature. His height was $110.4 \mathrm{~cm}(-2.4$ standard deviation score), with a target height of $177 \mathrm{~cm}(+0.35$ standard deviation score). Height corrected for target height was -2.75 standard deviation score. He presented with mild dysmorphic facial features, hypospadias and postnatal onset of severe growth retardation. Biochemical and endocrine tests were in the normal range. The child was exposed in utero to both carbamazepine and phenobarbital.

Conclusion: This case report shows for the first time that prenatal exposure to antiepileptic drugs may induce postnatal onset of severe growth retardation, suggesting the need for growth and endocrine monitoring of offspring exposed in utero to anticonvulsant drugs.
\end{abstract}

\section{Introduction}

Epilepsy is common, affecting $0.5 \%$ to $1 \%$ of the population. Of these, a third are women in reproductive age, and approximately 1 in 250 pregnancies are exposed to antiepileptic drugs. In utero exposure to antiepileptic drugs can result in several different teratogenic effects including major malformations, dysmorphic facial features, intrauterine growth retardation, learning and behavioral problems. We report on a child exposed in utero to both carbamazepine and phenobarbital. He presented with mild dysmorphic facial features, hypospadias and postnatal onset of growth retardation.

\section{Case presentation}

A 7-year-old boy presented to our clinic with short stature. His height was $110.4 \mathrm{~cm}(-2.4$ standard deviation score (SDS)), with a target height of $177 \mathrm{~cm}(+0.35$ SDS). Height corrected for target height was -2.75 SDS. His weight was $16.5 \mathrm{~kg}$. Body mass index (BMI) was 13.5 (-1.8 SDS). He was born at term after an uneventful pregnancy. Birth weight 
was $4260 \mathrm{~g}(+1.3 \mathrm{SDS})$, birth length was $53 \mathrm{~cm}$ (+1.1 SDS) and birth head circumference was $37 \mathrm{~cm}$ (+1.3 SDS). He was born with hypospadias and underwent surgery at the age of two years. During pregnancy, his mother had undergone antiepileptic therapy with carbamazepine (200 mg bid) and phenobarbital (100 mg bid). His growth was normal during the first 12 months of age, thereafter it slowed down progressively (Figure 1). On physical examination, ocular hypertelorism, arched eyebrows, epicanthal folds, broad nasal bridge, low-set ears, and shortness of the thumb were noted (Figure 2). Bone age was six years. Neurocognitive function was normal. Liver and renal function test results, electrolytes, calcium, phosphorus, and celiac disease markers were within the normal range. Urine examination was normal and thyroid function tests were normal. Arginine and growth hormone releasing hormone (GHRH) + arginine testing showed normal growth hormone (GH) responses ( $\mathrm{GH}$ peaks $25 \mu \mathrm{g} / \mathrm{L}$ and $25.3 \mu \mathrm{g} / \mathrm{L}$, respectively; normal values $\geq 10 \mu \mathrm{g} / \mathrm{L}$ and $20 \mu \mathrm{g} / \mathrm{L}$, respectively). Insulinlike growth factor-I (IGF-I) concentrations were in the low normal range (90 $\mu \mathrm{g} / \mathrm{L},-1.8$ SDS $)$, whereas IGFBP-3 levels were within the normal range $(2.9 \mathrm{mg} / \mathrm{L},+0.2 \mathrm{SDS})$. Renal and cardiac ultrasound scans were normal. Skeletal X-rays

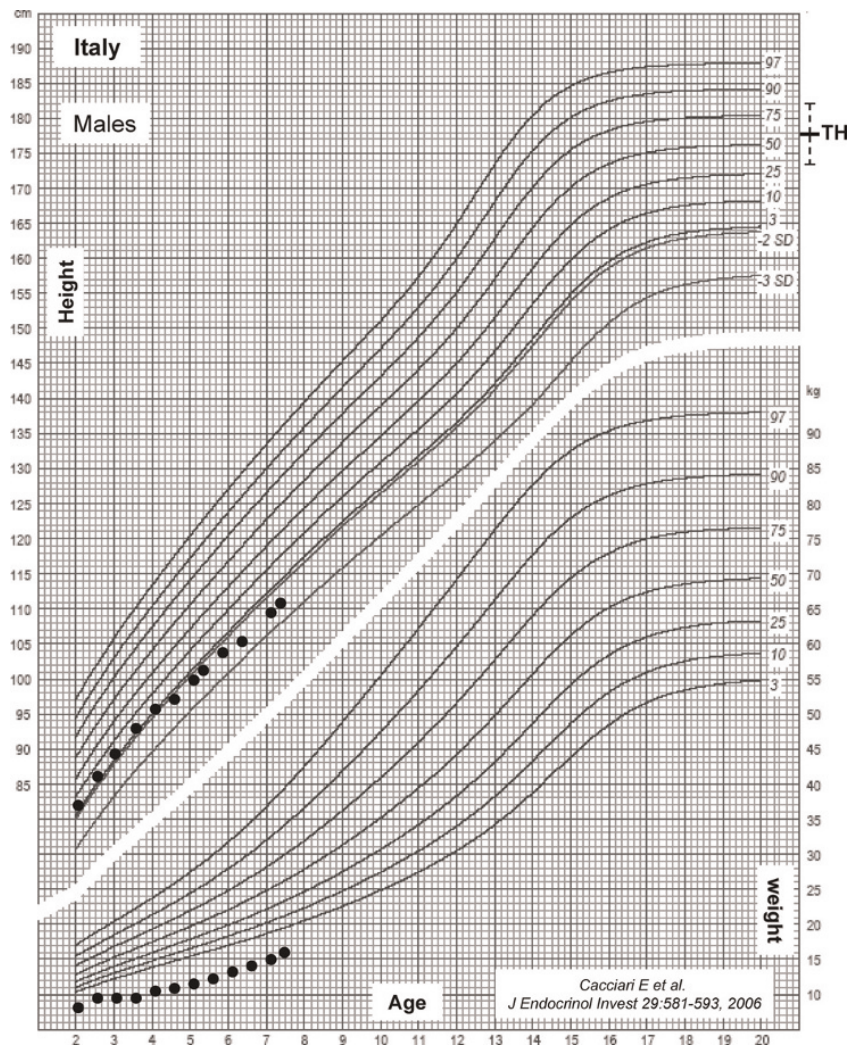

Figure I. Postnatal growth of the child exposed in utero to carbamazepine and phenobarbital.

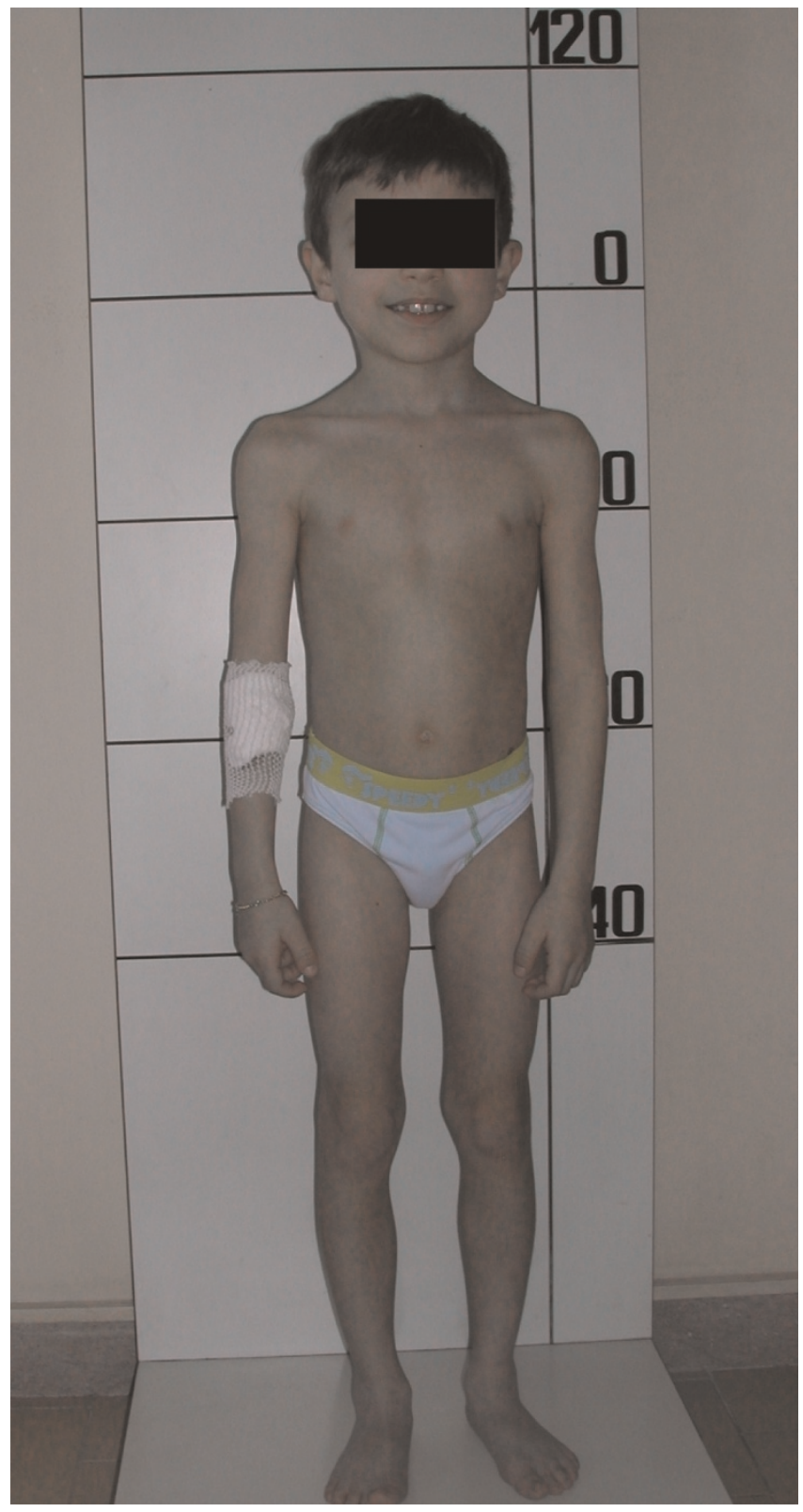

Figure 2. Patient's phenotype.

showed a short first metacarpal bone but no sign of skeletal dysplasias. Dysmorphologic evaluation did not reveal any particular syndrome. Chromosome analysis disclosed a normal 46,XY, karyotype.

\section{Discussion}

Data on the effects of prenatal exposure to carbamazepine and/or phenobarbital are conflicting. In a retrospective study of 375 children aged from six months to 16 years born to 219 mothers with epilepsy, Kini et al. [1] reported short stature in $6.5 \%$ of children exposed to 
carbamazepine and $6.4 \%$ of children exposed to polytherapy. In a prospective observational study across 25 epilepsy centers in the USA and UK, Meador et al. [2] observed that more adverse outcomes were observed in pregnancies with in utero valproate exposure. In children exposed in utero to carbamazepine, the following congenital malformations have been reported: absent kidney, duplicate renal pelvis, hypospadias, and inguinal hernia. In a cohort of female patients with epilepsy, Artama et al. [3] reported that the risk for congenital malformations was not elevated in offspring of mothers using carbamazepine, oxcarbazepine, or phenytoin (as monotherapy or polytherapy without valproate). In rats, Manent et al. [4] reported that prenatal exposure to vigabatrin and valproate, which act on GABA signaling, induces hippocampal and cortical dysplasias, which are likely to result from a neuronal migration defect and neuronal death. In contrast, offspring of rats exposed to carbamazepine showed no clear-cut evidence of dysplasias. Wide et al. [5] found a significant reduction in weight, head circumference and length, which tended to improve toward the first year and was marked in babies exposed to polytherapy and also in babies exposed to carbamazepine monotherapy. However, it has to be pointed out that nearly all studies on the adverse fetal effects of antiepileptic drugs have methodological shortcomings, including retrospective or inadequately prospective design, insufficient sample size, recruitment and assessment bias, limited length of follow-up, questionable choice of controls, and failure to account for potential confounders [6].

Our case is consistent with two previous reports showing either impaired physical growth in infants exposed to anticonvulsant drugs in utero in spite of normal birth size [7] or increased frequency of major malformations, microcephaly, and growth retardation in infants exposed to carbamazepine compared with control infants [8]. However, the severity of growth retardation and the full investigation of GH-IGF-I axis make our case unique. The finding of reduced IGF-I levels despite normal GH peak responses to stimulation tests raises the issue of a potential disrupting effect of the in utero antiepileptic exposure on postnatal GH-IGF-I axis function.

\section{Conclusion}

This case report shows for the first time that prenatal exposure to antiepileptic drugs may induce postnatal onset of severe growth retardation, thus suggesting the need for growth and endocrine monitoring of offspring exposed in utero to anticonvulsant drugs.

\section{Abbreviations}

$\mathrm{GH}$, growth hormone; GHRH, growth hormone releasing hormone; IGF-I, insulin-like growth factor-I; IGFBP-3, insulin-like growth factor binding protein-3.

\section{Consent}

Written informed consent was obtained from both parents of the patient for publication of this case report and any accompanying images. A copy of the written consent is available for review by the Editor-in Chief of this journal.

\section{Competing interests}

The authors declare that they have no competing interests.

\section{Authors' contributions}

$\mathrm{AL}$ and SC followed up the patient in the clinics, performed the literature review, drafted the manuscript, and read and approved the final version of the manuscript.

\section{References}

I. Kini U, Adab N, Vinten J, Fryer A, Clayton-Smith J: Dysmorphic features: an important clue to the diagnosis and severity of fetal anticonvulsivant syndromes. Arch Dis Child Fetal Neonatal Ed 2006, $91: 90-95$.

2. Meador KJ, Baker GA, Finnel RH, Kalayjian LA, Liporace JD, Loring DW, Mawer G, Pennell PB, Smith JC, Wolff MC for the NEAD Study Group: In utero antiepileptic drug exposure: fetal death and malformations. Neurology 2006, 67:407-4I2.

3. Artama M, Auvinen A, Raudaskoski T, Isojärvi I, Isojärvi J: Antiepileptic drug use of women with epilepsy and congenital malformations in offspring. Neurology 2005, 64:1874-1878.

4. Manent JB, Jorquera I, Mazzucchelli I, Depaulis A, Perucca E, BenAri Y, Represa A: Fetal exposure to GABA-acting antiepileptic drugs generates hippocampal and cortical dysplasias. Epilepsia 2007, 48:684-693.

5. Wide K, Winbladh B, Tomson T, Kallen B: Body dimensions of infants exposed to antiepileptic drugs in utero: observations spanning 25 years. Epilepsia 2000, 41:854-86I.

6. Perucca E: Birth defects after prenatal exposure to antiepileptic drugs. Lancet Neurol 2005, 4:78I-786.

7. Arulmozhi T, Dhanaraj M, Rangaraj R, Vengatesan A: Physical growth and psychomotor development of infants exposed to antiepileptic drugs in utero. Neurol India 2006, 54:42-47.

8. Holmes LB, Harvey EA, Coull BA, Huntington KB, Khoshbin $S$, Hayes AM, Ryan LM: The teratogenicity of anticonvulsant drugs. N Engl J Med 200I, 344: I I32-II38.

\section{Do you have a case to share?}

\section{Submit your case report today}

- Rapid peer review

- Fast publication

- PubMed indexing

- Inclusion in Cases Database

\section{Any patient, any case, can teach us something}

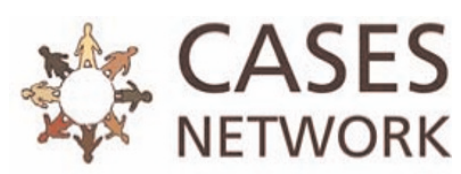

www.casesnetwork.com 